EPiC Series in Built Environment
Volume 1, 2020, Pages 81-89
Associated Schools of Construction Proceed-
ings of the 56th Annual International Conference

\title{
Relative Trends Associated with the International Journal of Construction Education and Research
}

\author{
Clifton B. Farnsworth, Ph.D., P.E. and Evan D. Bingham, Ph.D. and James P. Smith. Ph.D. \\ Brigham Young University \\ Provo, Utah
}

The International Journal of Construction Education and Research (IJCER) is an academic peerreviewed journal supported by the Associated Schools of Construction, publishing scholarly work associated with construction education and research. One challenge the IJCER has faced since its inception is establishing itself as a high quality, scholarly impactful publication. The purpose of this paper is to explore the relative trends associated with the IJCER, including the current state of academic impact metrics, a relative comparison of papers published by author and institution, and international and collaborative efforts. The results of this research indicated that the IJCER continues to improve its academic stature through increasing impact metrics. Since the inception of the IJCER in 2004, a total of 479 unique authors, representing 158 different institutions have been associated with IJCER papers. International and collaborative efforts have also been strongly represented and continue to be one of the strengths of the journal. This information can be used to help identify similar publishing peer groups and justify relative scholarly impact for those who publish in the IJCER. This research also identifies the breadth of impact the Associated Schools of Construction is providing its membership by sponsoring an academic peer reviewed journal.

Key Words: IJCER, ASC, Academic Impact, Construction Research, Collaboration

\section{Introduction}

It is an age-old adage that academics must "publish or perish." As the various disciplines in higher education associated with construction (construction management, construction technology, construction engineering, architecture, and civil engineering) continue to evolve, it seems that the "publish or perish" mantra continues to become more mainstream (especially for institutions with a research component). It is reasonably apparent that one of the purposes of an institution of higher education is to prepare students with the knowledge and skills necessary to enter the workforce. In other words, dissemination of knowledge to students. However, another element of higher education is the discovery and advancement of knowledge (Brown and McCartney,1998). Construction within higher education seems to be caught at a crossroads, as many institutions are beginning to place a heavier emphasis on scholarly endeavors from the faculty to help discover and advance knowledge within the construction related disciplines. 
One specific challenge of existing at an institution with scholarly expectations is the ill-defined level of impact of construction scholarship using traditional scholarly metrics. This seems to be a function of two elements: first, there seems to be a relatively small number of researchers publishing over a very broad range of topics compared to other academic disciplines; second, it seems that construction related research is finally beginning to take root as an established scholarly discipline. These two elements are certainly not mutually exclusive. The authors of this paper were recently confronted with this premise from their college administration, and subsequently challenged to begin to perform more impactful construction related scholarship. However, as part of this effort, it was readily apparent that the authors first needed to establish a better understanding of the relative impact of the scholarship that they have been involved with. The currency of impactful scholarship is typically measured in some combination of generated external research funding, publications produced, and graduate students advised. Although there are definitely other ways to develop scholarship and measure impact, these seem to be the most common metrics that institutions requiring scholarship measure impact. Two of the indirect measures the authors are frequently asked include "who are your peers?" and "what are they doing?" Being able to answer these questions is especially important when it comes to shepherding faculty through the tenure and promotion process.

The purpose of this paper is to begin to explore and define the relative impact of scholarship that is occurring within the International Journal of Construction Education and Research (IJCER), the academic journal sponsored by the Associated Schools of Construction (ASC). There were two principal goals associated with this research: first, to gain a better understanding of academic impact metrics and identify the IJCER's current state of impact; second, exploring the publication statistics of the IJCER to comparatively analyze the contributing authors and institutions, as well as international and collaborative efforts. This paper is in no way attempting to imply author or program superiority by more frequent publication. Rather, the intention is to simply allow institutions to more accurately define their peer group and establish a relative comparison, within the context of their individualized scholarly expectations. This research is also useful in identifying the reach the ASC is providing its membership through sponsoring an academic peer reviewed journal.

\section{Background}

There is a growing consensus amongst academics that the ways we measure scholarly performance and research impact is changing (Cronin and Subimoto, 2014). In short, the different variables and metrics typically used to measure scholarly output include inherent limitations that must be counterbalanced with the purpose of measuring scholarly impact in the first place. In a growing age of instant access to digital information, the more traditional methods of measuring impact are being challenged. Although the way to measure scholarly impact will certainly continue to evolve, for now, the authors simply note the importance of peer review and peer involvement within that process. For example, it is well established that appropriate peer review is an essential element in ensuring quality scholarly efforts (Chanson, 2007; Nicholas et al., 2015). With this in mind, one of the key purposes of this paper is to identify those most heavily involved with publishing in the IJCER. This is because these institutions not only significantly contribute to the "peer review" process, but also serve as the peer institutions for those publishing regularly in this particular journal.

The Associated Schools of Construction (ASC) is an organization of approximately 150 construction related programs from higher education institutions, that "promotes the sharing of ideas and knowledge and inspires, guides and promotes excellence in curricula, teaching, research and service" (ASC, 2019a). The ASC vision and mission statement both include scholarship related statements, including "inspiring excellence in research" and "advancing construction education by supporting 
members in research innovation," respectively (ASC, 2019b). It is readily apparent that one of the purposes of the ASC is to support the scholarship endeavors of its member institutions and the construction discipline in general. One of the ways that the ASC specifically promotes quality construction related scholarship is by sponsoring a peer reviewed academic journal. The idea of an academic journal sponsored by the ASC was first proposed in 1991, and took a number of years before it actually came to fruition with the inaugural publication of the Journal of Construction Education (JCE) in 1996 (Williamson, 2017). In 2004 - 05 the journal transitioned a name change to the International Journal of Construction Education and Research (IJCER), and began to be published in its current form by Taylor and Francis a year later, in 2006 (Williamson, 2017).

The International Journal of Construction Education and Research defines itself as "a respected international refereed journal that publishes original works addressing cutting edge, global issues in construction" (IJCER, 2019a). Note, one of the key aspirations of the IJCER is to be an international journal, presumably interpreted as being a journal that both publishes work from around the world as well as produces published work that is utilized by individuals and institutions around the world. Therefore, another key purpose of this paper is exploring the level of international and other collaborative efforts within IJCER publications. Also note the emphasis on work addressing cutting edge, global issues, implying the desire for high-quality impactful published research. The journal further "recognizes scholarly work in the areas of construction education and construction research by preserving and disseminating research (both quantitative and qualitative)" (IJCER, 2019a).

The scope of the IJCER "embraces pedagogical and industry content through a broad spectrum of construction-related topics including but not limited to: materials and methods, estimating, contracts, construction law, dispute resolution, labor, equipment, productivity, workforce development, project management, alternative delivery methods, building and information technology, automation and robotics, mechanical and electrical systems, sustainability, planning, decision-making, risk management, specialty subcontracting, scheduling, international construction and globalization, and procurement and project logistics" (IJCER, 2019a). This list of topics represents the broad spectrum that construction related research encompasses. However, this also makes the journal potentially inclusive of about any construction related scholarly endeavor undertaken, assuming that the rigorous scholarly standards expectant of IJCER manuscripts are met. This breadth seems to make sense, given the diversity of construction related programs represented within the ASC membership. However, it also represents one of the challenges the IJCER faces in increasing traditional scholarly metrics. Although, not a key part of this research, one area for future research is better defining the types of topics that have been published within the IJCER.

Impact factors tend to be somewhat controversial within higher education. However, they continue to be used by institutions as a gauge of scholarly impact, especially as part of the tenure and promotion process for faculty with heavier research expectations. The authors note that academic impact can (and should) be measured in many ways, and this brief discussion is only included in the paper as a relative comparison of traditional academic impact indicators. Readers should use their own discretion when referencing these sort of publication metrics. The Journal Citation Reports (JCR) impact factor is the most established impact factor utilized. An impact factor alone should not be used as the sole measure of scholarly impact; but rather, because of variability in the different disciplines and citation frequencies, the impact factor should be used with informed peer review (Clarivate Analytics, 2019). Unfortunately, the IJCER has not qualified for a JCR impact factor, a combination of the relative newness of the journal and historically low citation counts. However, the IJCER is continuously striving to publish quality papers that contribute to and influence the overall body of knowledge. In short, as IJCER publications become increasingly cited in other impactful publication venues, the IJCER academic impact will continue to improve and it should qualify for a JCR impact factor. 
In the interim, however, other common online metrics can serve as an indicator of the increasing quality of the IJCER. For example, the SCImago Journal and Country Rank (SJR) indicators are developed from information contained in the Scopus database, a respected science related abstract and citation database (SCImago, 2019a). There are a number of different SCImago indicators provided for the IJCER (SCImago, 2019b). Two examples of these relative metrics are shown in Figure 1. The SJR indicator is a measure of scientific influence that accounts for the number of citations received by a journal and the prestige of the journals where the citations come from (SCImago, 2019b). The current SCImago SJR indicator currently ranks the IJCER within the second quartile of all Building and Construction related journals, up recently from the third and fourth quartiles where the IJCER has historically resided. The citations per document indicator shows the average number of times documents published within the past two years have been cited within the current year. This is equivalent to the JCR impact factor (SCImago, 2019b) discussed above, and essentially measures the immediate influence that collective published works are having on the body of knowledge. Although the relative comparison of these metrics can be weighed against other disciplinary similar academic journals through this database, of most importance to note in this paper is the relative increasing trend of these measures of impact. Figure 1 demonstrates the increasing scholarly impact of the IJCER.

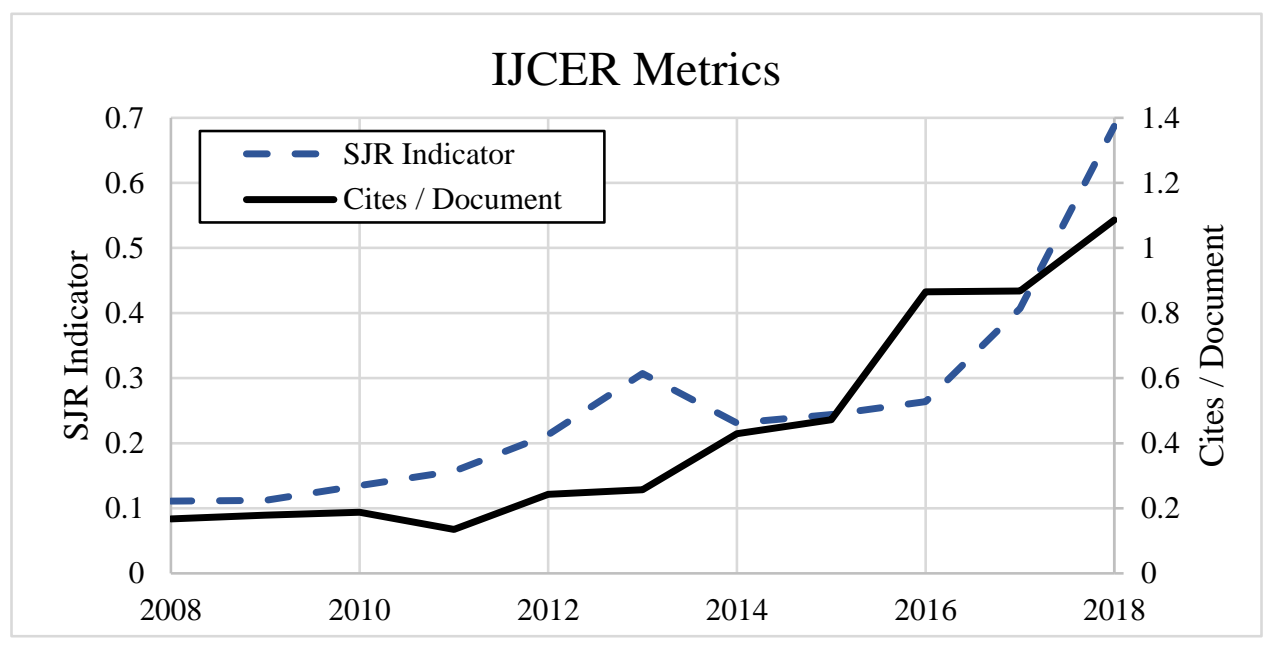

Figure 1. Example metrics for the IJCER (after SCImago, 2019b)

\section{IJCER Publication Statistics}

The IJCER has published a total of 260 unique manuscripts (as of September 1, 2019), and these papers comprise the complete dataset analyzed for this paper. Volume 1 was published in 2004 and 2005, and the papers associated with it are available through the journal archives page at the ASC website (ASC, 2019c). Taylor and Francis began publishing the IJCER with volume 2, and all IJCER papers (besides volume 1) can be found at the IJCER webpage (IJCER, 2019b). A total of 244 papers are included in volumes $1-15$; however, 16 additional papers have also been accepted, are currently published online, and are included within this analysis.

One of the key elements of this research was exploring who publishes in the IJCER and identifying where they are from. The purpose of this part of the analysis was to investigate the breadth of the community of scholars publishing in the IJCER. Although the information published in the IJCER has 
the potential to benefit construction education at large, sponsoring the IJCER also positively affects the academic goals of the scholars and institutions of those publishing in the IJCER. Therefore, this information helps define the reach the IJCER is having on individuals and institutions with regard to their scholarly endeavors. A total of 479 unique authors have published in the IJCER. 358 (74.7\%) of these authors were affiliated with U.S. based institutions, while the remaining 121 authors (25.3\%) were associated with institutions residing outside of the U.S. This data begins to validate the "international" nature of the IJCER. Of the 479 different authors, 376 (78.5\%) have had their name associated with only a single manuscript, while the highest two publishing authors have published 13 and 9 manuscripts, respectively. Figure 2 shows a breakdown of the number of papers that have been published by the corresponding number of authors. For example, $2.7 \%$ of the contributing authors have published 5 or more papers, $3.1 \%$ have published 4 papers, etc. Unfortunately, the authors do not know how this breakdown in authorship compares to other peer journals. Although beyond the scope of this research, this type of analysis could be performed with a more complete comparison of IJCER metrics with other peer journals. This breakdown does, however, provide two key pieces of information: first, many individuals have been able to publish within the IJCER, an indicator of the large community of scholars using the IJCER as a publication venue; second, 103 different authors (21.5\%) have been involved with multiple IJCER publications. This seems to indicate that publishing in the IJCER is providing value for a reasonably sized community of scholars, because they choose to come back. It should be noted that a number of authors published from multiple institutions during this time period, but the information shown accounts for these changes. Although a list of the highest publishing authors is not provided, it generally correlates with the highest publishing institutions.

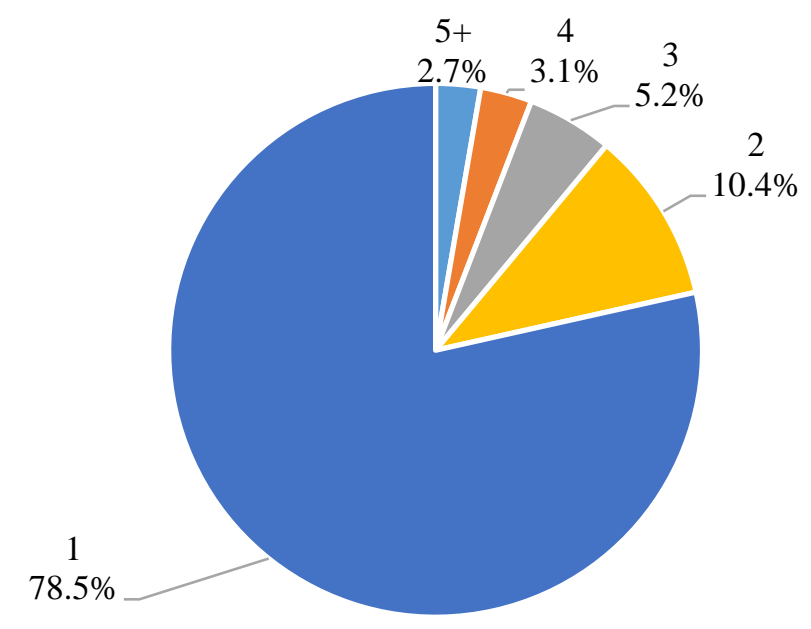

Figure 2. Number of papers published by contributing authors

Table 1 shows the highest number of papers associated with contributing institutions. Each unique institution affiliation for each paper was counted within this data. For example, Colorado State University has been associated with 40 different IJCER papers since the IJCER began in 2004. The data is based on the institutions for which each author was affiliated with at the time of publication. A total of 158 different institutions were associated with IJCER publications. This list generally represents institutions with a more significant research expectation, as indicated by the Carnegie research designation shown in Table 1 (R1 and R2 for doctoral granting universities with very high and high research activity, respectively). However, it should not be presumed that a university not appearing at the top of the list is not performing research. Rather, this list simply represents those 
institutions that are publishing the most in the IJCER. It should be noted that Williamson and Burt (2006) discuss a similar study performed on ASC journal publications occurring between 1996 and 2005. As such, this study predominantly involved data from the Journal of Construction Education (the predecessor to the IJCER, as described above), but did include some minor overlap with the IJCER. It is interesting to note that the top publishing institutions in the ASC journal during that time period continue to be the top publishing institutions in the current study, as indicated by the asterisk shown in Table 1. Generally speaking, the differences in Table 1 and the table in the Williamson and Burt (2006) study occur with the institutions shown at the bottom of both lists.

Table 1

Highest number of papers published by contributing institutions

\begin{tabular}{lc}
\hline \multicolumn{1}{c}{ Institution } & Number of Papers \\
\hline *Colorado State University (R1) & 40 \\
*Texas A\&M University (R1) & 23 \\
*Virginia Polytechnic Institute and State University (R1) & 16 \\
*Auburn University (R1) & 15 \\
*Arizona State University (R1) & 14 \\
*Brigham Young University (R2) & 13 \\
*Purdue University (R1) & 13 \\
*University of Florida (R1) & 12 \\
*University of Nebraska - Lincoln (R1) & 11 \\
*University of Oklahoma (R1) & 11 \\
Georgia Institute of Technology (R1) & 8 \\
Missouri State University & 8 \\
*Florida International University (R1) & 6 \\
University of North Carolina at Charlotte (R2) & 6 \\
University of Salford & 5 \\
Iowa State University (R1) & 4 \\
Michigan State University (R1) & 4 \\
Washington State University (R1) & 4 \\
\hline
\end{tabular}

*Indicated as a top publisher in the Williamson and Burt (2006) study

Table 2 shows a further delineation of the types of institutions that were associated with publishing in the IJCER. Ultimately, the purpose of this part of the analysis was to identify how many different academic institutions were publishing in the IJCER, but various authors were also associated with government, research, or industry organizations, as shown in Table 2. The government and research organizations were lumped together, since several of them had dual designation (government research organization). As expected, the majority of the 158 contributing institutions are made up of academic institutions. A smaller number of authors were associated with government, research, or private industry organizations. It is presumed that the majority of the individuals associated with nonacademic institutions fit one of the following two categories: first, former students who were now working for these other organization types, or second, collaborators from these other organization types that were working with the university on the research. Another purpose of this portion of the analysis was to provide a comparison of the U.S. with non-U.S. based organizations (herein referred to as "international"). Table 2 indicates that the number of contributing U.S. academic institutions (74) is not all that far ahead of the contributing international academic institutions (52). The majority of the U.S. based academic institutions are members of the Associated Schools of Construction 
(ASC). However, there are significantly more contributing international institutions than international based ASC member institutions. This means that the reach of the IJCER is broader than the boundaries of the ASC, and that it truly is an international publication as indicated within the name of the journal. The highest contributing international countries and the associated number of academic institutions from each country includes the United Kingdom (13), Australia (6), India (4), Malaysia (4), Canada (3), and South Africa (3).

Table 2

Breakdown of contributing institutions

\begin{tabular}{ccc}
\hline Institution Type & US & International \\
\hline Academic & 74 & 52 \\
Government / Research & 6 & 4 \\
Industry & 16 & 6 \\
Total & 96 & 62 \\
\hline
\end{tabular}

To further validate the international nature of the IJCER, a total of 22 different countries were represented in the publication affiliation information. This list includes the following: Australia, Canada, China, Denmark, Finland, Hong Kong, India, Indonesia, Jordan, Malaysia, Netherlands, New Zealand, Nigeria, Pakistan, Puerto Rico, Singapore, South Africa, Sri Lanka, Sweden, Thailand, United Kingdom, and the United States. The authors note that Puerto Rico is a U.S. territory, but chose to identify it separately in this list. The international presence (especially new submittals for peer review) with the IJCER continues to grow, and has really strengthened within the past few years. It is generally assumed that a growing presence of international related submittals correlates with a growing international presence of the journal being read and used. Analysis of web traffic utilizing the IJCER webpage to access articles further validates this claim. Although this list of affiliated countries supports the international nature of the IJCER, it further appears that there is yet significant room to grow the international presence of the IJCER.

Table 3

Collaborative and international involvement

\begin{tabular}{ccc}
\hline TITLE & Number of Papers & Percentage \\
\hline Collaboration (Multiple Organizations) & 110 & $42.3 \%$ \\
One International Author & 58 & $22.3 \%$ \\
Fully International & 44 & $16.9 \%$ \\
International Collaboration & 21 & $8.1 \%$ \\
\hline
\end{tabular}

One of the final elements explored within this research was the collaborative nature of the research being submitted for publication in the IJCER, including international collaboration. Table 3 shows that of the 260 unique manuscripts published, 110 of those papers included some form of collaborative effort. This means that over $40 \%$ of the papers submitted included author affiliation with two or more different institutions. Again, in some cases, these numbers certainly represent former students that were now working elsewhere. However, a large portion of these papers also certainly represent authors from multiple institutions that were working together on the research. Collaboration is inherently important because it has the potential to provide an additional layer of self-supported 
peer review, thus generally leading to a higher quality of research performed. Table 3 also shows that 58 papers $(22.3 \%)$ included at least one author affiliated with an institution outside of the U.S., and 44 of the published papers $(16.9 \%)$ were authored strictly by authors outside of the U.S. These numbers further validate the international nature of the IJCER. Finally, 21 papers $(8.1 \%)$ included some element of international collaboration, that is at least two of the authors were affiliated with institutions residing in different countries. Promoting an increase of this latter statistic also seems like an area that the ASC can promote.

The final element explored within this research was an analysis the various institutions that have been involved with the editorial process associated with the journal. This includes individuals who have served as editors, managing editors, associate editors, or editorial board members. 49 different institutions are represented within this group, of which 17 institutions have had multiple faculty members participate. Table 4 shows the institutions with the highest number of faculty involvement with the editorial process of the IJCER. To elevate and maintain quality of IJCER publications, editorial related assignments are often delegated to individuals with significant research and publishing experience (in other words, individuals from institutions with heavier scholarship expectations). However, to maintain diversity of academic thought and strong peer review, as well as to continue to grow the overall quality of construction research being performed across ASC member institutions, editorial related assignments must continue to be spread over a broad range of individuals and institutions. This also appears to be an area in which the ASC can continue to promote.

Table 4

Faculty involvement with IJCER editorial assignments

\begin{tabular}{cc}
\hline Institution & Number of Faculty \\
\hline Colorado State University & 8 \\
Brigham Young University & 6 \\
Clemson University & 5 \\
University of Oklahoma & 5 \\
Purdue University & 4 \\
University of Florida & 4 \\
University of Nebraska - Lincoln & 4 \\
Washington State University & 4 \\
\hline
\end{tabular}

\section{Conclusions}

Supporting the production of the IJCER is an essential service provided by the Associated Schools of Construction. Although not all ASC member institutions have the same scholarly expectations, the IJCER provides a publication venue for those who have journal publication requirements. Either way, the idea behind generating and sharing information related to furthering construction education and knowledge supports the mission of the ASC. One of the challenges the IJCER has seemed to face since its inception is establishing itself as a high quality, high impactful publication. The purpose of this paper has been to explore some of the nuances that provide better understanding regarding these challenges. This paper has demonstrated some of the key trends associated with the relative impact of the IJCER. In summary, the IJCER is trending upward with regard to traditional scholarly impact metrics. The IJCER has been a publishing resource for 479 unique authors, representing 158 different institutions. International and collaborative efforts have been strongly represented and continue to be 
one of the strengths of the journal. The international presence seems to help validate the importance of the journal in construction related research. Ultimately, this research has identified the breadth of impact the Associated Schools of Construction is providing its membership by sponsoring an academic peer reviewed journal. The information contained within this paper can be used by individuals and institutions to help identify similar publishing peer groups and justify relative scholarly impact for those who publish in the IJCER.

\section{References}

ASC (2019a). Associated Schools of Construction, General Information webpage: https://www.ascweb.org/about/general-information/ (accessed 10/29/2019).

ASC (2019b). Associated Schools of Construction, Vision and Mission Statements webpage: https://www.ascweb.org/about/mission-statement/ (accessed 10/29/2019).

ASC (2019c). Associated Schools of Construction, ASC Journal Archives webpage: http://www.ascjournal.ascweb.org/archive/ (accessed 10/29/2019).

Chanson, H. (2007). Research Quality, Publications, and Impact in Civil Engineering into the 21st Century. Publish or Perish, Commercial versus Open Access, Internet versus Libraries? Canadian Journal of Civil Engineering, 34(8), 946-951.

Clarivate Analystics (2019). The Clarivate Analytics Impact Factor webpage:

https://clarivate.com/webofsciencegroup/essays/impact-factor/ (accessed 10/29/2019).

Cronin, B. and Sugimoto, C.R. (Eds.) (2014). Beyond Bibliometrics: Harnessing Multidimensional Indicators of Scholarly Impact. MIT Press.

IJCER (2019a). International Journal of Construction Education and Research, Aims and Scope webpage: https://www.tandfonline.com/action/journalInformation?show=aimsScope\&journalCode $=$ uice20 $($ accessed 10/29/2019).

IJCER (2019b). International Journal of Construction Education and Research webpage: https://www.tandfonline.com/toc/uice20/current (accessed 10/29/2019).

Nicholas, D., Watkinson, A., Jamali, H.R., Herman, E., Tenopir, C., Volentine, R., Allard, S., and Levine, K. (2015). Peer Review: Still King in the Digital Age. Learned Publishing, 28(1), 15-21.

SCImago (2019a). SJR — SCImago Journal \& Country Rank, About Us webpage: https://www.scimagojr.com/aboutus.php (accessed 10/29/2019)

SCImago (2019b). SJR — SCImago Journal \& Country Rank, IJCER webpage: https://www.scimagojr.com/journalsearch.php?q=144811\&tip=sid (accessed 10/29/2019)

Williamson, K. (2017). History of ASC Publications. https://www.ascweb.org/ascwp/wpcontent/uploads/2018/02/ASC-Publications-History.pdf (accessed 10/29/19).

Williamson, K. and Burt, R.A. (2006). Continuing the Ranking Game: Using ASC Publication as One Criteria for the Ranking of C-Schools. ASC Annual Conference Proceedings. 